\title{
Analysis of prevalence and prognosis of type 2 diabetes mellitus in patients with acute exacerbation of COPD
}

\author{
Li Lin, Jianxin Shi, Jian Kang and Qiuyue Wang*
}

\begin{abstract}
Background: For patients with acute exacerbation of COPD (AECOPD), type 2 diabetes mellitus (T2DM) as comorbidity have poor outcomes. However, data on the impact of previously diagnosed and new- diagnosed T2DM in such a patient population is lacking.

Methods: Inpatients diagnosed with AECOPD in the department of Pulmonary and Critical Care Medicine of The First Hospital of China Medical University during 2011-2017 were enrolled. Data on demography, prevalence of type 2 DM, other comorbidities, hospital stays and laboratory tests (including arterial partial pressure of oxygen [PaO2]) results were recorded. Results were compared with AECOPD patients having previously diagnosed and new-diagnosed type 2 diabetes. Markers associated with development of type 2 DM and the prognosis of AECOPD patients were identified.

Results: Of the 196 patients enrolled in this study, the overall prevalence of T2DM was 26\%. The PaO2 in the newly diagnosed T2DM group was considerably lower versus non-diabetic group. The T2DM group had a longer hospital stay and higher troponin level versus the non-diabetic group. AECOPD patients with T2DM were found to be correlated with hypertension. Age, need for assisted ventilation, increased troponin, and elevated fasting blood glucose on admission were risk factors for death in hospitalized AECOPD patients.

Conclusions: AECOPD patients had a higher prevalence of T2DM than the general population; T2DM comorbidity caused lower PaO2, longer hospital stays, and increased troponin. Poor blood glucose control may increase the risk of death in AECOPD patients.
\end{abstract}

Keywords: COPD, Acute exacerbation of COPD, Diabetes mellitus, Coronary heart disease, Hypertension, Short-term prognosis

\section{Background}

Chronic Obstructive Pulmonary Disease (COPD) exhibits persistent respiratory symptoms and airflow limitation, seriously affecting the quality of the patient's life. Its prevalence and mortality rates are rising rapidly; the latest statistics indicate that the prevalence of COPD in

\footnotetext{
*Correspondence: qywang2002@hotmail.com
}

Department of Pulmonary and Critical Care Medicine, Institute

of Respiratory Disease, The First Hospital of China Medical University, No.

155 Nanjing Street, North, Shenyang 110001, China people aged $\geq 40$ in China is $13.7 \%$ [1] and $8.9 \%$ in America [2]. WHO estimates that by 2020 COPD may become the third leading cause of fatality in the world [3, 4], eventually leading to a huge social and economic burden.

Acute exacerbation is the leading cause of hospitalization and mortality among COPD patients. Severe exacerbation is linked to a high risk of early mortality and a median survival of only 3.6 years [5]. COPD is also often linked to several other chronic disease conditions, such as osteoporosis, cardiovascular disease, and metabolic syndrome [6-9]. Of these, D.M. is one of the 
most frequent and severe comorbidities. Several studies explored the incidence and prognosis of D.M. among AECOPD patients; the diagnosis of D.M. among patients hospitalized for AECOPD was about 22\% in Australia [10], 18\% in Switzerland [11], 22\% in Taipei [12], and a high of $40 \%$ in India [13]. An investigation conducted in Finland, focusing on AECOPD among patients using inhaled beta-2-adrenergic bronchodilators and oral glucocorticoid, the prevalence of hyperglycemia was found to reach up to $82 \%$ [14]. These data were comparatively much higher than those in the general population [15, 16]. Comorbidity with hyperglycemia may cause even worse prognosis for AECOPD; the risk of hospital stay and death increases by $7-15 \%$ for each $1 \mathrm{mmol} / \mathrm{L}$ increment in blood glucose concentration $[17,18]$. Hyperglycemia has been evidenced to cause a lowered quality of life, high risk of pneumonia, high risk of intensive care admission, lowered lung function, high risk of coronary heart disease (CHD), hypertension, and mortality among AECOPD patients [10,18-20]. Nevertheless, little effort has been made to recognize the incidence and effect of T2DM among AECOPD patients, or the differences between previously diagnosed and newly diagnosed T2DM in Mainland China.

The prevalence of $\mathrm{T} 2 \mathrm{DM}$ in hospitalized patients with AECOPD in China, factors that cause T2DM in AECOPD patients, the impact of T2DM on various indicators and prognosis of AECOPD patients, and the association with other comorbid diseases such as CHD and hypertension, with AECOPD with T2DM, have been explored. The difference between previously-diagnosed and newly diagnosed T2DM also has been discussed in this study.

\section{Methods}

\section{Research subjects}

This prospective observational study was conducted in patients diagnosed with AECOPD in the department of Pulmonary and Critical Care Medicine of the First Affiliated Hospital of China Medical University who were enrolled during 2011-2017. The ethics committee of the first hospital of China Medical University approved this study. This study was conducted according to the guidelines of the Declaration of Helsinki.

\section{Inclusion criteria and grouping Diagnosis of COPD}

All the patients confirmed to the clinical characteristics of COPD. Patients underwent lung function tests and exhibited a post-bronchodilator FEV1/FVC ratio of $<0.70$. Patients exhibiting severe disease symptoms for whom lung function examination could not be performed at the time of hospitalization were diagnosed by a consultant in the respiratory department based on smoking history, medical history, clinical manifestations, and patients' imaging manifestations. Most of the patients have confirmed the diagnosis through pulmonary function examination at the time of discharge.

\section{Diagnosis of AECOPD}

AECOPD was characterized by worsening of the COPD patient's respiratory symptoms such as cough, sputum, shortness of breath, wheezing, increased sputum volume, and purulent or purulent mucus, and can be associated with fever and other symptoms that are beyond normal day-to-day variations, acute in onset, and requires a change in regular medication [21].

\section{Diagnosis of T2DM}

A definite previous diagnosis of diabetes, and using a hypoglycemic agent or undergoing insulin treatment at present; fasting blood glucose $\geq 7.0 \mathrm{mmol} / \mathrm{L}$, or random blood glucose $\geq 11.1 \mathrm{mmol} / \mathrm{L}$ or OGTT $2 \mathrm{~h} \geq 11$ in two tests conducted at 2 different times were the techniques used for diagnosing T2DM. Diagnosis of T2DM excluded the cases who exhibited normal blood glucose on admission and abnormal glucose metabolism caused by systemic application of glucocorticoid after admission and those diagnosed with T1DM.

\section{Grouping}

Based on the criteria mentioned above, all the patients were segregated into 3 groups: patients diagnosed with AECOPD alone were categorized into group A, patients with AECOPD and new diagnosed T2DM into group B, and patients with AECOPD and previously diagnosed T2DM were categorized under group C.

\section{Exclusion criteria}

Patients suffering from a pulmonary embolism, pneumothorax, malignant tumor, or other serious blood system diseases were excluded from the study.

\section{Patient's general information and blood test}

Data on the general information, clinical diagnosis, and concomitant diseases of patients such as CHD and hypertension were collected from the information gathered at admission diagnosis, auxiliary examination, and discharge diagnosis in the First Affiliated Hospital of China Medical University.

The outcomes of fasting blood glucose performed on the first morning of admission prior to treatment on that day were considered. The arterial partial pressure of oxygen $(\mathrm{PaO} 2)$ values of all patients were in the deoxygenated state as detected on admission. 


\section{Statistical analysis}

SPSS 17.0 statistical software was used for statistical analysis, and the measured data were expressed as mean \pm standard deviation $(x \pm S D)$. Analysis of normal distribution data was performed using variance. The nonnormal distribution data were analyzed using the ranksum test; the Chi-square test was used for the analysis of the correlation of CHD and hypertension with diabetes. The analyses of risk factors related to T2DM as comorbidity were performed using logistic regression analysis (The female was assigned a value of 1 , and the male was assigned 0 ; smoking was assigned 1 , and non-smoking 0 ; respiratory failure was assigned 1 , and no respiratory failure $0, \mathrm{PaO} 2$ and age were evaluated as a numerical variable). The analyses of risk factors for in-hospital deaths were also performed using logistic regression analysis (The variables were grouped and assigned values: $0.04 \mathrm{ng} /$ $\mathrm{ml}$ troponin was used as a threshold, $>0.04$ was assigned a value of 1 , and $<0.04$ was assigned 0 ; diabetes group was assigned 1 in and without diabetes 0; smoking1, while non-smoking 0 ; needing mechanical ventilation 1 , not needing mechanical ventilation 0 . Age, $\mathrm{PaO} 2$, and blood glucose levels were calculated as numerical variables). A value of $p<0.05$ was considered statistically significant.

\section{Result}

\section{Effect of AECOPD comorbidity with T2DM on clinical} characteristics of patients

Clinical characteristics of patients of all the groups are provided in Table 1.
This study included 196 AECOPD patients, in which the total prevalence of AECOPD with T2DM was $26.02 \%$, with $12.76 \%$ newly diagnosed and $13.27 \%$ previously diagnosed T2DM, respectively. The prevalence rates of female and male patients were $29.58 \%$ and $24 \%$, respectively. Overall, $31.12 \%$ of AECOPD patients suffered hypertension, $26.02 \%$ of AECOPD patients suffered CHD, $6.63 \%$ of AECOPD patients suffered from all the 3 diseases T2DM, hypertension, and CHD. The incidences of hypertension and CHD were much higher in the previously diagnosed diabetes group than in groups without diabetes and newly diagnosed diabetes.

The $\mathrm{PaO} 2$ in the newly diagnosed diabetes group was recorded to be lower than that of the group without diabetes $(p<0.01)$, and also the $\mathrm{PaO} 2$ in the diabetic group (Group B + Group $C$ ) was observed to be lower than that in the non-diabetic group (Group A) $(p<0.01)$.

The troponin level in previously diagnosed T2DM group (Group $C$ ) was higher than the non-diabetic group (Group A) and newly diagnosed T2DM group (Group B) $(p<0.05)$.

The hospital stay period was remarkably extended in patients diagnosed earlier with diabetes compared with those without diabetes and with newly diagnosed diabetes $(\mathrm{p}<0.05)$.

During this investigation, 16 patients died, with a case fatality rate of $8.16 \%$; mortality rate without diabetes was $6 \%$, and with diabetes was $13.73 \%$, in which newly diagnosed diabetes was $16 \%$, and previously diagnosed diabetes was $12 \%$.

Table 1 Baseline characteristics for the total population and each group (mean \pm standard deviation)

\begin{tabular}{|c|c|c|c|c|}
\hline Variable & Group A & Group B & Group C & Group B + C \\
\hline Total population (\%) & $145(73.98)$ & $25(12.76)$ & $26(13.27)$ & $51(26.02)$ \\
\hline Male gender (\%) & $95(66)$ & $16(12.8)$ & $14(10.94)$ & $30(24)$ \\
\hline Female gender (\%) & $50(70.42)$ & $9(12.68)$ & $12(16.9)$ & $21(29.58)$ \\
\hline Age & $72.43 \pm 8.97$ & $72.36 \pm 8.48$ & $71.00 \pm 8.99$ & $71.65 \pm 9.76$ \\
\hline Course of disease & $17.09 \pm 13.51$ & $15.04 \pm 12.04$ & $17.88 \pm 12.82$ & $16.55 \pm 1.95$ \\
\hline Hospital stays & $13.58 \pm 7.88$ & $12.80 \pm 8.43$ & $19.37 \pm 11.25$ *\# & $16.71 \pm 13.49$ \\
\hline Death (\%) & $9(6)$ & $4(16)$ & $3(12)$ & $7(13.73)$ \\
\hline \multicolumn{5}{|l|}{ Comorbidities } \\
\hline Hypertension (\%) & $39(27)$ & $7(28)$ & $15(58)$ & $22(43.13)$ \\
\hline $\mathrm{CHD}(\%)$ & $31(21)$ & $7(28)$ & $13(50)$ & $20(39.22)$ \\
\hline \multicolumn{5}{|c|}{ Laboratory values (at admission) } \\
\hline Troponin (ng/ml) & $0.09 \pm 0.29$ & $0.11 \pm 0.39$ & $0.37 \pm 0.06$ *\# & $0.25 \pm 0.45$ \\
\hline D-Dimer $(\mu \mathrm{g} / \mathrm{mL})$ & $1.94 \pm 2.11$ & $1.61 \pm 1.13$ & $1.52 \pm 0.86$ & $1.56 \pm 1.49$ \\
\hline $\mathrm{PaO} 2(\mathrm{mmHg})$ & $60.98 \pm 15.05$ & $51.66 \pm 13.54^{* *}$ & $57.11 \pm 14.83$ & $55.98 \pm 14.19^{*}$ \\
\hline $\mathrm{Hb}(\mathrm{g} / \mathrm{l})$ & $130.28 \pm 20.41$ & $131.04 \pm 13.57$ & $128.42 \pm 27.78$ & $130.02 \pm 29.51$ \\
\hline BNP $(\mathrm{pg} / \mathrm{ml})$ & $318.39 \pm 625.66$ & $414.16 \pm 705.81$ & $384.38 \pm 761.74$ & $399.47 \pm 799.45$ \\
\hline
\end{tabular}

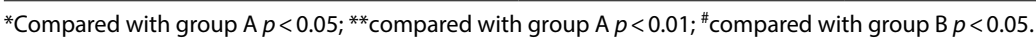

CHD Coronary heart disease 
Correlation analysis indicated that AECOPD patients with T2DM were linked with increased troponin levels.

\section{Association of AECOPD comorbid diabetes with hypertension and CHD}

The correlation between AECOPD with T2DM and the prevalence of hypertension and CHD were analyzed. AECOPD comorbidity with T2DM was not found to be linked to CHD. Nevertheless, in this study, AECOPD with diabetes was observed to be positively correlated with hypertension, suggesting that patients with AECOPD and T2DM were more likely to suffer from hypertension than patients with AECOPD alone (Table 2).

\section{Reduced $\mathrm{PaO} 2$ positively related to comorbid T2DM}

The possible risk factors such as smoking, age, gender, $\mathrm{PaO} 2$ reduction, and respiratory failure with the occurrence of T2DM in AECOPD patients were considered in this study. Results indicated that all the above factors could not be considered risk factors for patients previously diagnosed with T2DM. In the case of newly diagnosed patients with T2DM, reduced $\mathrm{PaO} 2$, and respiratory failure at admission were risk factors for diabetes (Table 3).

\section{Elevated fasting blood glucose at admission is one of the risk factors for in-hospital deaths}

Risk factors such as old age, need for mechanical ventilation, comorbid T2DM, increased troponin levels, smoking status, and low $\mathrm{PaO} 2$ on the incidence of in-hospital deaths were evaluated.

After excluding other confounding factors, the factors such as old age, need for assisted ventilation, and elevated

Table 2 Comorbidity with diabetes on the prevalence of hypertension of AECOPD patients

\begin{tabular}{lllll}
\hline & Hypertension & $\begin{array}{l}\text { Normal blood } \\
\text { pressure }\end{array}$ & $\mathbf{x}^{\mathbf{2}}$ & $\boldsymbol{p}$ \\
\hline Group B +C & 22 & 29 & 4.642 & 0.031 \\
Group A & 39 & 106 & & \\
\hline
\end{tabular}

Table 3 Risk factors analysis of comorbid newly diagnosed diabetes

\begin{tabular}{llllll}
\hline & B & S.E & Wals & OR & $\boldsymbol{p}$ \\
\hline PaO2 & -0.039 & 0.016 & 6.051 & 0.961 & 0.014 \\
Smoking & 0.998 & 0.584 & 2.918 & 2.712 & 0.088 \\
Gender & 0.272 & 0.510 & 0.284 & 1.313 & 0.594 \\
Age & -0.008 & 0.027 & 0.081 & 0.992 & 0.775 \\
RF & 1.432 & 0.532 & 0.468 & 3.975 & 0.024 \\
\hline
\end{tabular}

RF Respiratory Failure, $B$ partial regression coefficient, S.E. standard error, Wals Wald test statistic, $O R$ odds ratio
Table 4 Risk factors analysis for in-hospital death(s)

\begin{tabular}{lcllll}
\hline & B & S.E & Wals & OR & $\boldsymbol{p}$ \\
\hline Age & 0.139 & 0.05 & 7.567 & 1.149 & 0.006 \\
Troponin & 2.088 & 0.665 & 9.863 & 8.067 & 0.002 \\
Smoking & -0.041 & 0.772 & 0.003 & 0.960 & 0.957 \\
PaO2 & -0.038 & 0.023 & 2.652 & 0.963 & 0.103 \\
Diabetes & 0.835 & 0.650 & 1.649 & 2.304 & 0.199 \\
Ventilation & 2.341 & 0.804 & 8.475 & 10.396 & 0.004 \\
\hline
\end{tabular}

$B$ partial regression coefficient, S.E. standard error, Wals Wald test statistic, $O R$ odds ratio

troponin posed as risk factors for death in hospitalized AECOPD patients. However, comorbid diabetes does not pose a direct risk factor for hospitalized AECOPD patients' death (Table 4). After excluding the confounding factors in the diagnosis of diabetes, increased fasting blood glucose on admission was found to be a risk factor for the death of COPD hospitalized patients.

\section{Discussion}

In the current study, we found that the prevalence of T2DM increased in AECOPD patients, and AECOPD patients with diabetes exhibited a lower $\mathrm{PaO} 2$ level, increased troponin levels, and the possibility of hypertension. Lower $\mathrm{PaO} 2$ level also acts as a risk factor for diabetes. Risk factors for deaths during hospitalization among AECOPD patients comprise high fasting blood glucose during admission, elevated troponin, old age, and the need for assisted ventilation. Poor glycemic control influences the short-term prognosis of AECOPD patients.

AECOPD patients are at a significantly higher risk of developing T2DM than the general population [14, 22-24] and vice versa [25]. Comorbidity with T2DM has been reported to deteriorate the progression and prognosis of AECOPD patients [26].

T2DM incidence with hospitalized AECOPD patients in this study was $26.02 \%$, which is higher than those reported in Europe and America [18, 27]. In this study, the prevalence of diabetes was $29.57 \%$ in females and $24.0 \%$ in male patients, which agree with earlier research [25]. Patients with previously diagnosed diabetes accounted for $13.27 \%$ of all surveyed AECOPD patients, whereas newly diagnosed diabetes accounted for $12.76 \%$.

Hyperglycemia is not a well-explored therapeutic target in AECOPD. Several factors contribute to the link between AECOPD with T2DM and its adverse events [28]. First, the use of systemic and high-dose inhaled glucocorticoids in the treatment of AECOPD could likely raise the incidence of occurrence and progress of hyperglycemia [29-31], although a combined therapy of ICS and a $\beta 2$-agonist may reduce this association [32]. 
Second, comorbidity with T2DM could raise pulmonary infection incidence, a major risk factor for AECOPD [33]. Third, hypoxia [34, 35], acidosis [36], systemic inflammatory response [28], and stress [14, 33, 37] among AECOPD patients could trigger the glucose-elevating hormones and lead to the occurrence of hyperglycemia. Fourth, hyperglycemia also could have adverse effects on the lungs because it is likely to stimulate the glycosylation of connective tissues, reduce pulmonary elastic recoil, cause weakness and/or inflammation in respiratory muscles, and susceptibility to bacterial infection, which increase the risk of AECOPD [38-41]. Fifth, chronic hyperglycemia also can induce systemic vascular and nerve damage on lung histopathology, and lung function changes consistently with the systemic microvascular disease [42]. Last, hypoglycemia raises the aggregation of blood platelets and fibrinogen formation, which may speed up the vascular damage in the lung and cause a higher risk for in-hospital complications and longer hospitalizations [43, 44].

In this study, patients with T2DM exhibit a lower $\mathrm{PaO} 2$, whereas patients with newly diagnosed T2DM show even lower $\mathrm{PaO} 2$ than patients with preexisting T2DM. Moreover, regression analysis indicated that a lower $\mathrm{PaO} 2$ and respiratory failure were risk factors for AECOPD patients with newly developed T2DM. It is incomprehensive to identify the reasons for the damage to pulmonary dispersion function caused by diabetes, as the effect of high blood glucose on small airway and the effect of pulmonary dispersion functions progress over time. The correlation between hypoxemia and abnormal glucose tolerance has been explored [9], and oxygen therapy was found to improve the glucose tolerance of AECOPD patients significantly. Although the normal $\mathrm{PaO} 2$ levels could not be restored, there was a remarkable difference compared with that before the therapy. However, Oltmanns et al. found that reducing blood oxygen saturation to $75 \%$ of its original level in healthy subjects within $30 \mathrm{~min}$ added abnormal glucose tolerance. The mediating cause of abnormal glucose tolerance is attributable to elevated levels of adrenaline [35]. In an earlier investigation, increased adrenalin secretion has been reported to likely cause an increase in serum adrenalin levels among patients with AECOPD acute episode [45]. Hypoxemia and the rise in $\mathrm{PaO} 2$ caused by oxygen therapy are likely to influence the concentration of catecholamines in blood, which can rapidly influence the sensitivity of peripheral tissues to insulin. It could be assumed that the reason for the prevalence of diabetes in this study to be higher than that reported in the above-mentioned investigation is the stress caused by AECOPD, causing a high catecholamine secretion, thus influencing glucose tolerance. Nevertheless, the difference in $\mathrm{PaO} 2$ values between patients with newly diagnosed T2DM and patients with previously diagnosed T2DM may cause abnormal glucose tolerance and even the diagnosis of diabetes, rather than vice versa. The 2 factors may also be mutually promoting, and further investigations are obligatory.

Troponin level in T2DM group was found to be higher than that in the non-diabetic group as per the statistical outcomes of this study, and in agreement with the existing research results, troponin was found to be one of the risk factors for the death of hospitalized patients [46]. Thus, T2DM may indirectly influence the prognosis of hospitalized AECOPD patients, of course, as observed in this investigation. Age and the level of blood glucose control also influence the incidence of T2DM in AECOPD patients, and in the end, influence the prognosis of patients, which is more worthy of attention. Only 7 of the 27 patients with elevated troponin were diagnosed with CHD, and 20 had no history or manifestation of CHD. Troponin elevation is the most sensitive and specific biochemical indicator of ischemic myocardial injury. However, non-ischemic myocardial injury-related pathological conditions such as sepsis, pulmonary embolism, viral myocarditis, and renal failure are also likely to occur, and as one of the critical factors influencing longterm prognosis [47]. The autonomic nervous system dysfunction causes overactivation of the sympathetic nerve and an increase in catecholamine effect in cardiomyocytes. Injury to myocardial cells resulting from trauma or inflammation is part of the possible mechanism, and hypoxemia may also cause myocardial injury. Moreover, among AECOPD patients, these are most likely occurrences.

In this study, AECOPD with T2DM was positively correlated with hypertension, which means that when AECOPD patients suffer from T2DM, patients are more likely to have hypertension, which deserves more attention. It was not evidenced that T2DM was a risk factor for CHD in AECOPD patients because the association between T2DM and CHD was not statistically significant in this study, which was not in agreement with several earlier reports in T2DM patients. We attribute this to inadequate clinical diagnosis of CHD or sample size, and also COPD is an independent risk factor for CHD because they share some same systemic inflammatory mechanisms [48], which may weaken the connection between D.M. and CHD in AECOPD patients in this study.

Poor control of diabetes has been reported to relate to a higher prevalence of AECOPD, and poor control of diabetes of hospitalized patients can prolong the length of hospital stay and increase the probability of 
complications due to comorbidities and in-hospital mortality, including cardiovascular deaths [3].

Aged, need for assisted ventilation, and elevated troponin were risk factors for death in hospitalized AECOPD patients. These results were consistent with findings of earlier studies [18, 49]; however, comorbid T2DM does not pose a direct risk factor for hospitalized AECOPD patients' death. As fasting blood glucose higher than $11.0 \mathrm{mmol} / \mathrm{l}$ at admission has been evidenced to pose a risk factor for hospitalized deaths of AECOPD patients [18]. A simple analysis of whether a patient has diabetes or not may inadequate to evaluate patients' blood glucose levels since even patients with T2DM may have different blood glucose control conditions. Therefore, we calculated the correlation between the death of hospitalized patients and fasting blood glucose. After excluding the confounding factors in the diagnosis of diabetes, increased fasting blood glucose on admission was found to be a risk factor for the death of COPD hospitalized patients.

AECOPD patients are at a higher risk of T2DM than the general population, which may increase these AECOPD patients' short-term mortality, especially in the newly diagnosed T2DM group. We found that AECOPD patients with newly diagnosed T2DM suffer from lower $\mathrm{PaO} 2$. As lower $\mathrm{PaO} 2$ is also an independent risk factor for T2DM, $\mathrm{PaO} 2$ levels should be carefully observed among AECOPD patients, and oxygen therapy is necessary for patients with AECOPD combined with hypoxia, which is likely to reduce the incidence of T2DM. When AECOPD patients have T2DM as comorbidity, they were more likely to suffer from hypertension than CHD; in that case, we should pay more attention to their blood pressure. Old age, need for assisted ventilation, elevated troponin, and increasing fasting blood glucose increase the short-term mortality in hospitalized AECOPD patients; in that case, AECOPD patients with abnormal blood glucose should be prioritized; early detection and timely control and oxygen therapy are some of the effective measures that are eventually beneficial to patients with diabetes in terms of improving their quality of life.

\section{Conclusion}

The prevalence of diabetes increased in AECOPD patients, and AECOPD patients with diabetes exhibited a lower $\mathrm{PaO} 2$ level, increased troponin levels, and the possibility of hypertension. Lower $\mathrm{PaO} 2$ level also acts as a risk factor for diabetes. Risk factors for deaths during hospitalization among AECOPD patients comprise high fasting blood glucose during admission, elevated troponin, old age, and the need for assisted ventilation. Poor glycemic control influences the short-term prognosis of AECOPD patients. AECOPD patients with diabetes and abnormal blood glucose should be prioritized; early detection and timely control as well as oxygen therapy are some of the effective measures that are eventually beneficial to patients with diabetes in terms of improving their quality of life.

\section{Abbreviations}

T2DM: Type 2 diabetes mellitus; T1DM: Type 1 diabetes mellitus; AECOPD: Acute exacerbation of COPD; COPD: Chronic obstructive pulmonary disease; PaO2: Arterial partial pressure of oxygen; D.M.: Diabetes mellitus; CHD: Coronary heart disease; OGTT: Oral glucose tolerance test; FEV1: Forced expiratory volume in the first second; FVC: Forced vital capacity.

\section{Acknowledgements \\ Not applicable.}

\section{Authors' contributions}

WQY and K.J. contributed to experimental design and statistical analysis, And L.L. and SJX contributed to data collection and document writing. All authors have read and approved the final manuscript.

\section{Funding}

This work was in part supported by National Key Technology Research and Development Program of the 13th National 5-year Development Plan (2016YFC1304103) and (2016YFC1304502). The funders had no role in study design, data collection and analysis, decision to publish, or preparation of the manuscript.

\section{Availability of data and materials}

The datasets used and/or analyzed during the current study are available from the corresponding author on reasonable request.

\section{Ethics approval and consent to participate}

This study was approved by the ethics committee of the first affiliated hospital of Chinese Medical University (Reference number:AF-SOP-07-1.1-01). This study was conducted according to the guidelines of the Declaration of Helsinki. All the individuals gave their written informed consent to participate.

\section{Consent for publication}

Not applicable.

\section{Competing interests}

The authors declared no competing interests.

Received: 11 June 2020 Accepted: 11 December 2020

Published online: 06 January 2021

\section{References}

1. Wang C, Xu J, Yang L, Xu Y, Zhang X, Bai C, Kang J, Ran P, Shen H, Wen F, et al. Prevalence and risk factors of chronic obstructive pulmonary disease in China (the China Pulmonary Health [CPH] study): a national crosssectional study. Lancet (London, England). 2018;391(10131):1706-17.

2. Raju S, Brigham EP, Paulin LM, Putcha N, Balasubramanian A, Hansel NN, McCormack MC. The burden of rural COPD: Analyses from the National Health and Nutrition Examination Survey (NHANES). Am J Respir Crit Care Med. 2019;2019:219.

3. Viegi G, Scognamiglio A, Baldacci S, Pistelli F, Carrozzi L. Epidemiology of chronic obstructive pulmonary disease (COPD). Respiration. 2001:68(1):4-19.

4. Vestbo J, Hurd SS, Agusti AG, Jones PW, Vogelmeier C, Anzueto A, Barnes PJ, Fabbri LM, Martinez FJ, Nishimura M, et al. Global strategy for the diagnosis, management, and prevention of chronic obstructive pulmonary disease: GOLD executive summary. Am J Respir Crit Care Med. 2013;187(4):347-65. 
5. Suissa S, Dell'Aniello S, Ernst P. Long-term natural history of chronic obstructive pulmonary disease: severe exacerbations and mortality Thorax. 2012;67(11):957-63.

6. Martinez $\mathrm{CH}$, Han MK. Contribution of the environment and comorbidities to chronic obstructive pulmonary disease phenotypes. Med Clin North Am. 2012;96(4):713-27.

7. Ho TW, Huang CT, Ruan SY, Tsai YJ, Lai F, Yu CJ. Diabetes mellitus in patients with chronic obstructive pulmonary disease-The impact on mortality. PLoS ONE. 2017;12(4):e0175794.

8. Smith MC, Wrobel JP. Epidemiology and clinical impact of major comorbidities in patients with COPD. Int J Chron Obstruct Pulmon Dis. 2014;9:871-88

9. Diez-Manglano J, Recio Iglesias J, Varela Aguilar JM, Almagro Mena P, Zubillaga Garmendia G. Effectiveness of a simple intervention on management of acute exacerbations of chronic obstructive pulmonary disease and its cardiovascular comorbidities: COREPOC study. Med Clin (Barc). 2017;149(6):240-7.

10. Parappil A, Depczynski B, Collett P, Marks GB. Effect of comorbid diabetes on length of stay and risk of death in patients admitted with acute exacerbations of COPD. Respirology. 2010;15(6):918-22.

11. Flattet $Y$, Garin N, Serratrice J, Perrier A, Stirnemann J, Carballo S. Determining prognosis in acute exacerbation of COPD. Int J Chron Obstruct Pulmon Dis. 2017;12:467-75.

12. Lee MC, Lee $\mathrm{CH}$, Chien SC, Chang JH, She HL, Wang JY, Yu MC. Inhaled corticosteroids increase the risk of pneumonia in patients with chronic obstructive pulmonary disease: a nationwide cohort study. Medicine (Baltimore). 2015;94(42):e1723.

13. Rambaran K, Bhagan B, Ali A, Ali F, Toolsie S, Lobin R, Beharry S, Ghany S, Mohammed S, Davis G, et al. High prevalence of diabetes mellitus in a cohort of patients with chronic obstructive pulmonary disease in Trinidad, West Indies. Turk Thorac J. 2019;20(1):12-7.

14. Koskela HO, Salonen PH, Niskanen L. Hyperglycaemia during exacerbations of asthma and chronic obstructive pulmonary disease. Clin Respir J. 2013;7(4):382-9.

15. Xu G, Liu B, Sun Y, Du Y, Snetselaar LG, Hu FB, Bao W. Prevalence of diagnosed type 1 and type 2 diabetes among U.S. adults in 2016 and 2017: population based study. BMJ. 2018;362:k1497.

16. Anjana RM, Deepa M, Pradeepa R, Mahanta J, Narain K, Das HK, Adhikari P, Rao PV, Saboo B, Kumar A, et al. Prevalence of diabetes and prediabetes in 15 states of India: results from the ICMR-INDIAB population-based cross-sectional study. Lancet Diabetes Endocrinol. 2017;5(8):585-96.

17. Koskela HO, Salonen $\mathrm{PH}$, Romppanen J, Niskanen L. A history of diabetes but not hyperglycaemia during exacerbation of obstructive lung disease has impact on long-term mortality: a prospective, observational cohort study. BMJ Open. 2015;5(1):e006794.

18. Baker EH, Janaway CH, Philips BJ, Brennan AL, Baines DL, Wood DM, Jones PW. Hyperglycaemia is associated with poor outcomes in patients admitted to hospital with acute exacerbations of chronic obstructive pulmonary disease. Thorax. 2006;61(4):284-9.

19. Lin CS, Liu CC, Yeh CC, Chang YC, Chung CL, Lane HL, Shih CC, Chen TL, Liao CC. Diabetes risks and outcomes in chronic obstructive pulmonary disease patients: two nationwide population-based retrospective cohort studies. PLOS ONE. 2017:12(8):e0181815.

20. Rubinsztajn R, Przybylowski T, Grabicki M, Karwat K, MaskeyWarzechowska M, Batura-Gabryel H, Chazan R. Comorbidities in chronic obstructive pulmonary disease: results of a national multicenter research project. Adv Clin Exp Med. 2019;28(3):319-24.

21. Rodriguez-Roisin R. Toward a consensus definition for COPD exacerbations. Chest. 2000;117(5 Suppl 2):398s-401s.

22. Parappil A, Depczynski B, Collett P, Marks GB. Effect of comorbid diabetes on length of stay and risk of death in patients admitted with acute exacerbations of COPD. Respirology (Carlton, Vic). 2010;15(6):918-22.

23. Flattet $Y$, Garin N, Serratrice J, Perrier A, Stirnemann J, Carballo S. Determining prognosis in acute exacerbation of COPD. Int J Chronic Obstr Pulmonary Dis. 2017;12:467-75.

24. Rambaran K, Bhagan B, Ali A, Ali F, Toolsie S, Lobin R, Beharry S, Ghany S, Mohammed S, Davis $G$, et al. High prevalence of diabetes mellitus in a cohort of patients with chronic obstructive pulmonary disease in Trinidad, West Indies. Turk Thor J. 2019:20(1):12-7.

25. Hsu IL, Lu C-L, Li C-C, Tsai S-H, Chen C-Z, Hu SC, Li C-Y. Population-based cohort study suggesting a significantly increased risk of developing chronic obstructive pulmonary disease in people with type 2 diabetes mellitus. Diabetes Res Clin Pract. 2018;138:66-74.

26. Gläser S, Krüger S, Merkel M, Bramlage P, Herth FJF. Chronic obstructive pulmonary disease and diabetes mellitus: a systematic review of the literature. Respir Int Rev Thorac Dis. 2015;89(3):253-64.

27. Winther JA, Brynildsen J, Høiseth AD, Følling I, Brekke PH, Christensen G, Hagve T-A, Verbalis JG, Omland T, Røsjø H. Prevalence and prognostic significance of hyponatremia in patients with acute exacerbation of chronic obstructive pulmonary disease: data from the akershus cardiac examination (ACE) 2 study. PLOS ONE. 2016;11(8):e0161232-e0161232.

28. Hitchings AW, Lai D, Jones PW, Baker EH. Metformin in severe exacerbations of chronic obstructive pulmonary disease: a randomised controlled trial. Thorax. 2016;71(7):587-93.

29. Suissa S, Kezouh A, Ernst P. Inhaled corticosteroids and the risks of diabetes onset and progression. Am J Med. 2010;123(11):1001-6.

30. Caughey GE, Preiss AK, Vitry Al, Gilbert AL, Roughead EE. Comorbid diabetes and COPD: impact of corticosteroid use on diabetes complications. Diabetes Care. 2013;36(10):3009-14.

31. Ceviker Y, Sayiner A. Comparison of two systemic steroid regimens for the treatment of COPD exacerbations. Pulm Pharmacol Ther. 2014;27(2):179-83.

32. Rogliani P, Calzetta L, Segreti A, Barrile A, Cazzola M. Diabetes mellitus among outpatients with COPD attending a university hospital. Acta Diabetol. 2014;51(6):933-40.

33. Yang CJ, Liao WI, Tang ZC, Wang JC, Lee CH, Chang WC, Hsu CW, Tang SE, Tsai SH. Glycated hemoglobin A1c-based adjusted glycemic variables in patients with diabetes presenting with acute exacerbation of chronic obstructive pulmonary disease. Int J Chron Obstruct Pulmon Dis. 2017;12:1923-32.

34. Louis M. Punjabi NM (2009) Effects of acute intermittent hypoxia on glucose metabolism in awake healthy volunteers. J Appl Physiol. 1985;106(5):1538-44

35. Oltmanns KM, Gehring H, Rudolf S, Schultes B, Rook S, Schweiger U, Born J, Fehm HL, Peters A. Hypoxia causes glucose intolerance in humans. Am J Respir Crit Care Med. 2004;169(11):1231-7.

36. Adrogue HJ, Chap Z, Okuda Y, Michael L, Hartley C, Entman M, Field JB. Acidosis-induced glucose intolerance is not prevented by adrenergic blockade. Am J Physiol. 1988;255(6 Pt 1):E812-823.

37. Oguntibeju O. Type 2 diabetes mellitus, oxidative stress and inflammation: examining the links. Int J Physiol Pathophysiol Pharmacol. 2019;11(3):45-63.

38. Kinney GL, Black-Shinn JL, Wan ES, Make B, Regan E, Lutz S, Soler X, Silverman EK, Crapo J, Hokanson JE. Pulmonary function reduction in diabetes with and without chronic obstructive pulmonary disease. Diabetes Care. 2014;37(2):389-95.

39. Davis WA, Knuiman M, Kendall P, Grange V, Davis TM. Glycemic exposure is associated with reduced pulmonary function in type 2 diabetes: the Fremantle Diabetes Study. Diabetes Care. 2004;27(3):752-7.

40. Lim SY, Rhee EJ, Sung KC. Metabolic syndrome, insulin resistance and systemic inflammation as risk factors for reduced lung function in Korean nonsmoking males. J Korean Med Sci. 2010;25(10):1480-6.

41. Lawlor DA, Ebrahim S, Smith GD. Associations of measures of lung function with insulin resistance and Type 2 diabetes: findings from the British Women's Heart and Health Study. Diabetologia. 2004;47(2):195-203.

42. Dalquen P. The lung in diabetes mellitus. Respiration. 1999:66(1):12-3.

43. Kasirye Y, Simpson M, Mamillapalli CK, Epperla N, Liang H, Yale SH. Association between blood glucose level and outcomes in patients hospitalized for acute exacerbation of chronic obstructive pulmonary disease. WMJ. 2013;112(6):244-9.

44. Kolahian S, Leiss V, Nürnberg B. Diabetic lung disease: fact or fiction? Rev Endocrine Metabolic Disord. 2019;20(3):303-19.

45. Hofford JM, Milakofsky L, Vogel WH, Sacher RS, Savage GJ, Pell S. The nutritional status in advanced emphysema associated with chronic bronchitis. A study of amino acid and catecholamine levels. Am Rev Respir Dis. 1990;141(4 Pt 1):902-8.

46. Baillard C, Boussarsar M, Fosse JP, Girou E, Le Toumelin P, Cracco C, Jaber S, Cohen Y, Brochard L. Cardiac troponin I in patients with severe exacerbation of chronic obstructive pulmonary disease. Intensive Care Med. 2003:29(4):584-9. 
47. Janata KM, Leitner JM, Holzer-Richling N, Janata A, Laggner AN, Jilma B. Troponin T predicts in-hospital and 1-year mortality in patients with pulmonary embolism. Eur Respir J. 2009;34(6):1357-63.

48. Parker D, Liu J, Roberts M, Eaton C. Is inflammatory chronic obstructive pulmonary disease a coronary heart disease risk equivalent? A longitudinal analysis of the third National Health and Nutrition Examination Survey (NHANES III), 1988-1994. BMC Pulmonary Med. 2014;14:195.

49. Brekke PH, Omland T, Holmedal SH, Smith P, Soyseth V. Determinants of cardiac troponin T elevation in COPD exacerbation - a cross-sectional study. BMC Pulm Med. 2009;9:35.

\section{Publisher's Note}

Springer Nature remains neutral with regard to jurisdictional claims in published maps and institutional affiliations.
Ready to submit your research? Choose BMC and benefit from:

- fast, convenient online submission

- thorough peer review by experienced researchers in your field

- rapid publication on acceptance

- support for research data, including large and complex data types

- gold Open Access which fosters wider collaboration and increased citations

- maximum visibility for your research: over 100M website views per year

At BMC, research is always in progress.

Learn more biomedcentral.com/submissions 